\title{
əPossible Cause of Seasonal Inhomogeneity in Interdecadal Changes of Tropical Cyclone Genesis Frequency over the Western North Pacific $\mathscr{O}$
}

\author{
Minhee Chang, ${ }^{a}$ Doo-Sun R. Park, ${ }^{b}$ And Chang-Hoi $\mathrm{Ho}^{\mathrm{a}}$ \\ ${ }^{\text {a }}$ School of Earth and Environmental Sciences, Seoul National University, Seoul, South Korea \\ ${ }^{\mathrm{b}}$ Department of Earth Science Education, Kyungpook National University, Daegu, South Korea
}

(Manuscript received 16 April 2020, in final form 26 October 2020)

\begin{abstract}
An abrupt decrease in annual tropical cyclone genesis frequency (TCGF), which is statistically significant only from October to December (OND), has been noticed over the western North Pacific Ocean. However, the seasonal inhomogeneity of interdecadal changes in TCGF between OND and the other seasons (from January to September) and the associated mechanisms are not clearly documented. This study examines and compares the different interdecadal changes in OND and in January-September from 1979 to 2018. According to our analysis, the TCGF decrease in OND (2.2) accounts for $79 \%$ of the total decrease (2.8) in annual TCGF after 1998, whereas the TCGF in January to September remains unchanged. The key differences in large-scale environment are found from the extension of equatorial easterly wind anomalies and attendant anticyclone anomalies in the subtropics. Under similar sea surface temperature (SST) warming pattern in the tropical Indo-Pacific region (i.e., the La Niña-like SST warming), tropical precipitation is significantly enhanced over the area where its seasonal peak occurs: the tropical Indian Ocean in OND and the tropical western Pacific in January-September. Thus, the equatorial easterly wind anomalies extend westward to $110^{\circ} \mathrm{E}$ in $\mathrm{OND}$ and to $145^{\circ} \mathrm{E}$ in January-September. Different extension of easterly wind anomalies results in different expansion of attendant large-scale anticyclone anomaly over the subtropical western Pacific, which dominates the entire main development region in OND but not in January-September. To summarize, the different extensions of easterly wind anomalies under similar La Niña-like SST warming are responsible for the seasonal inhomogeneity of interdecadal changes in TCGF.
\end{abstract}

KEYWORDS: Tropical cyclones; Interdecadal variability

\section{Introduction}

Many studies reported a significant and abrupt reduction in tropical cyclone genesis frequency (TCGF) in the western North Pacific Ocean (WNP) from the late 1990s, despite local sea surface temperature (SST) increasing in the basin (Park et al. 2011; Liu and Chan 2013; He et al. 2015; Hong et al. 2016; Huangfu et al. 2017, 2018; Zhao et al. 2018). The reduction is seasonally inhomogeneous, as the significant TCGF decrease only occurs in the late season [October-December (OND)] (Hsu et al. 2014, 2017; Liu et al. 2019). Most previous studies, however, have focused on the late season's TCGF reduction, while understanding of the unchanged TCGF in the other seasons remains unclear.

Previous studies suggested that a long-term change in SST over the tropical Pacific is the primary driver for the recent TCGF reduction. In recent decades, tropical SSTs have been warmer in the west than in the east, and this is termed La Niñalike warming. This strengthens the zonal gradient of the SST,

๑ Denotes content that is immediately available upon publication as open access.

Supplemental information related to this paper is available at the Journals Online website: https://doi.org/10.1175/JCLI-D-200268.s1.

Corresponding author: Doo-Sun Park, dsrpark@knu.ac.kr thereby enhancing the Walker circulation (Park et al. 2013; Hsu et al. 2014; Choi et al. 2015). The enhanced Walker circulation promotes anomalous anticyclonic flow and strong vertical wind shear in the tropical western Pacific, with these representing unfavorable conditions for tropical cyclone (TC) formation (Liu and Chan 2013; Huangfu et al. 2018; Zhang et al. 2018; Zhao et al. 2018). In addition, the monsoon trough and synoptic-scale eddy activity over the western tropical Pacific are weakened, and thus contribute in suppressing TCGF (Hsu et al. 2017; Huangfu et al. 2017, 2018). However, the asymmetric SST warming pattern noted in recent decades was consistently found throughout the year (Zhang et al. 2011; Kosaka and Xie 2013; Kohyama et al. 2017), implying that other factors account for the seasonal inhomogeneity of the TCGF interdecadal changes.

In general, dynamic factors are acknowledged to exert a greater control on TC activity in the WNP than thermodynamic factors (Chan 2009; Fu et al. 2012; Park et al. 2013; Hsu et al. 2014). Thus, when the asymmetry in zonal SST is enhanced over the tropical Pacific, differential thermal forcing of SST can lead to the modification of the dynamic environment (Vecchi and Soden 2007). Contextually, we aim to explain the inhomogeneous seasonal response of the dynamic environment under similar SST warming patterns in this study. The data and method used in this study are described in section 2. In section 3, temporal and spatial analyses of TCGF changes and their relevance to the wider environment are presented, and the summary and conclusions are in section 4. 
(a) Yearly time series

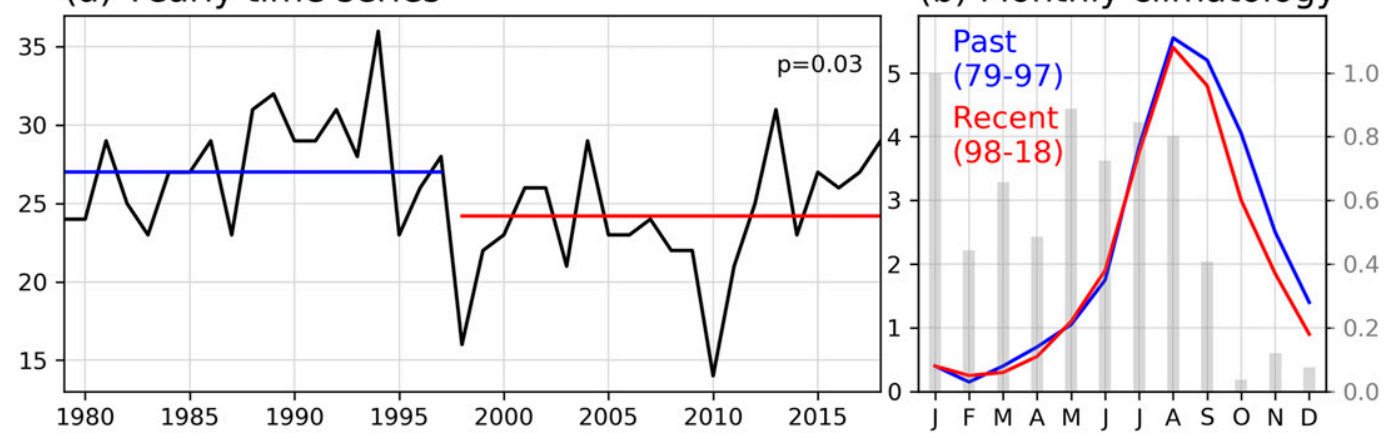

FIG. 1. (a) Yearly time series of tropical cyclone genesis frequency (TCGF) from 1979 to 2018 in the western North Pacific (WNP). The blue and red lines represent the average TCGF for the early (1979-97) and recent (19982018) periods, respectively. (b) Monthly distribution of tropical cyclones (TCs) (left axis) in the early (blue) and recent (red) periods. The Student's $t$ test $p$ value(s) between two periods are written in the top-right corner in (a) and are shown with gray bars (right axis) in (b).

\section{Data and method}

The spatial and temporal information associated with TCs in the WNP from 1979 to 2018 were obtained from the Regional Specialized Meteorological Center's (RSMC) best-track dataset (available at https://www.jma.go.jp/jma/jma-eng/jma-center/ rsmc-hp-pub-eg/besttrack.html). Any tropical disturbance that attained tropical storm strength in the RSMC record (10min maximum wind speed higher than $17 \mathrm{~m} \mathrm{~s}^{-1}$ ) was designated as a TC in this study. Here, to comprehend interdecadal changes in monthly TCGF, the months were first grouped into January-March (JFM), April-June (AMJ), July-September (JAS), and OND. For simplicity, the months were later divided into only two groups: January-September and OND. When calculating TCGF spatial distribution, we adopted the "overlap gridding" technique from Kim et al. (2010) and Park et al. (2013) to avoid sensitivity of the spatial patterns when shifting the grid centers. The TCGFs for each season were binned into $10^{\circ} \times 10^{\circ}$ latitude-longitude grid windows, shifting at $5^{\circ}$ intervals in latitude and longitude.

Three datasets related to the atmospheric and oceanic environments were investigated for the same period (1979-2018). The monthly zonal and vertical wind speed data at 27 pressure levels from 1000 to $100 \mathrm{hPa}$ were obtained at a horizontal resolution of $0.75^{\circ}$ from the reanalysis (ERA-Interim) data produced by the European Centre for Medium-Range Weather Forecasts (Dee et al. 2011). From the same reanalysis data, the 850 -hPa relative vorticity fields with a horizontal resolution of $0.75^{\circ}$ were obtained in 6-hourly intervals. The 20-day low-pass Butterworth filter was applied to the relative vorticity fields to eliminate small-scale eddies, including TCs. Monthly precipitation data were acquired from the Global Precipitation Climatology Project (GPCP), version 2.3, involving a $2.5^{\circ}$ horizontal resolution (Adler et al. 2003), and the SST data employed were from the National Oceanic and Atmospheric Administration Extended Reconstructed SST V5 with a horizontal resolution of $2^{\circ}$ (Huang et al. 2017).

The abrupt shift in annual and seasonal TCGF was objectively estimated using the statistical changing point analysis with confidence levels, which adopts the Student's $t$ test between two arbitrary groups (Chu 2002; Park et al. 2011). To confirm the robustness of TCGF change, we attempted several variations of Student's $t$ tests: nonsliding and sliding tests. A nonsliding Student's $t$ test examines significant difference in mean TCGF before and after a certain year despite the different sample sizes of two groups. A sliding $t$ test assigns a specific size of sliding window before and after a certain year and examines the significant difference of two groups with identical sample size. Here, we tested different lengths of sliding windows: 12,15 , and 18 years. The interdecadal changes in the atmospheric and the oceanic environments were also statistically examined by the Student's $t$ test.

\section{Results}

\section{a. Tropical cyclone genesis frequency}

According to RSMC best-track data for the last four decades, about 25.6 TCs on average occurred annually in the WNP, although the frequency decreases notably over the past 20 years. Several variations of statistical changepoint analysis show the consistent result that the annual mean TCGF decreased by 2.8 in the recent period (1998-2018) relative to the early period (1979-97) at the 95\% confidence level (Fig. 1a).

Although TCs occur throughout the year in the WNP, the recent monthly TCGF data exhibit significant decreases only in the late season of the year (Fig. 1b). Particularly, the Student's $t$-test $p$ values shown with gray bars in Fig. $1 \mathrm{~b}$ are clearly divided into two groups: larger than 0.4 in January-September versus smaller than 0.12 in October-December. The significant annual TCGF reduction is mostly accounted for by that in OND (i.e., 79\% of the total decrease). Meanwhile, the monthly TCGF is still highest in August and lowest in February for the early and recent periods, although interdecadal decrements are largely notable only in OND (Fig. 1b).

For comprehensive understanding of seasonal inhomogeneity of TCGF changes, interdecadal changes in seasonal TCGF are shown in Fig. 2. The JFM and AMJ periods exhibit negligible TCGF differences between the early and recent periods. The mean TCGF in JFM and AMJ is 0.9 and 3.5, 

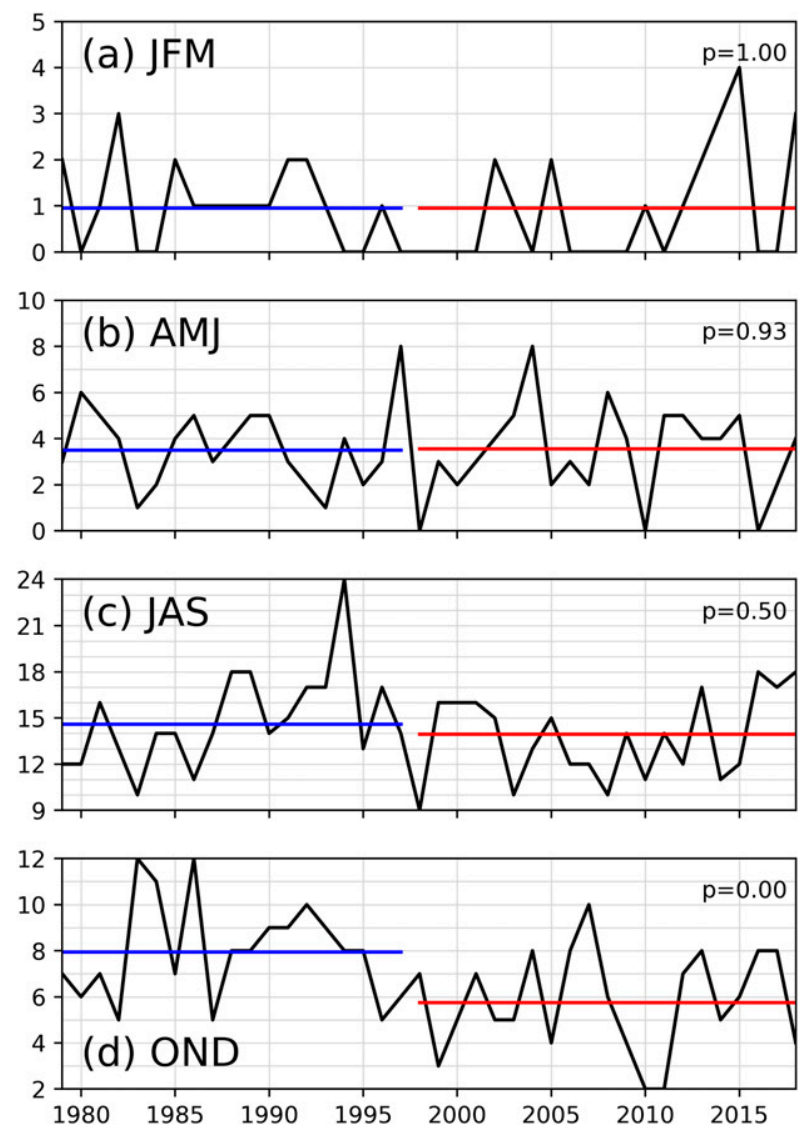

FIG. 2. Seasonal time series of TCGF from 1979 to 2018 for (a) JFM, (b) AMJ, (c) JAS, and (d) OND. The blue and red lines represent average TCs in the early (1979-97) and recent (19982018) periods, respectively. The $p$ values shown in the top-right corner of each plot are the statistical significance of changes in the average TCs between the two periods on the basis of the Student's $t$ test.

respectively, which is unchanged between the early and recent periods. JAS is the most active season for TC activity (about 14.3 in average), despite a slight decrease in TCGF (0.7) in the recent period, without statistical significance at the $95 \%$ confidence level. In OND, however, the 2.2 difference in TCGF is significant at the $95 \%$ confidence level. These results are consistent with previous studies reporting recent decrease in TCGF during the late season (e.g., Hsu et al. 2014; Fan et al. 2019). Among the several variations of statistical changepoint analysis, the sliding Student's $t$ test with a 12- or 15-yr window show that TCGF in JAS also decreases with $95 \%$ of significance. However, when the window gets larger, the significance is less robust, because the changes in JAS could possibly be due to the large values in the late 1980s to early 1990s. The TCGF changes in JAS occur on a shorter time scale than OND. Hence, on a longer time scale, the shift of annual mean TCGF in $1997 / 98$ is considered to be driven mainly by TCGF changes in OND.

The spatial distributions of TCGF for seasons are displayed in Fig. 3. In JFM, TCs generally occur in the far east of the
Philippines (black contours around $150^{\circ} \mathrm{E}$ ) close to the equator, but the absolute values are very low. Interdecadal changes (shadings) show a slight increase and decrease to the west and east of $150^{\circ} \mathrm{E}$, respectively, but without any significance (Fig. 3a). In AMJ, the TC main development region (MDR) extends from the South China Sea to the Philippines Sea in a northwest-southeast direction (black contours Fig. 3b). In the meridional direction, the MDR is located between latitudes $5^{\circ}$ and $25^{\circ} \mathrm{N}$. For interdecadal changes, a complex pattern of increases and decreases repeats over the MDR without any significance. The spatial distribution of MDR in JAS is the widest, with more frequent TC formation than in the other seasons (black contours Fig. 3c). The MDR expands over the entire WNP basin between latitudes $5^{\circ}$ and $35^{\circ} \mathrm{N}$ and from the South China Sea to the date line. Concerning the interdecadal changes, the increase and decrease in TCGF (shadings) are complexly distributed as in AMJ, without any statistical significance. Besides, such complex distribution in TCGF changes seems unrelated to any systematic change in largescale circulation for the time scale of two decades. Furthermore, the regional increases and decreases in TCGF offset each other, ultimately producing insignificant changes in seasonal TCGF as depicted in Fig. 2c. In OND, the zonal distribution of TC formation resembles that in JAS but the meridional distribution is restricted to the tropics from $0^{\circ}$ to $20^{\circ} \mathrm{N}$ (black contours in Fig. 3d). The interdecadal decreases in TCGF (shadings) occur within the majority of the MDR in this season, although small increases are present to the east of the Philippines without statistical significance. In specific terms, the TCGF decrease in the eastern Philippines Sea accounts for $74 \%$ of the entire TCGF decrease in OND while that in the South China Sea accounts for a minor portion (23\%). Also, the TCGF decrease in the eastern Philippines Sea presents with 95\% significance, whereas that in the South China Sea does not. In other words, the change in TCGF over the eastern Philippines Sea is the most responsible for the abrupt TCGF decrease in OND.

\section{b. Large-scale environment assessment}

To understand possible reasons for the seasonal inhomogeneity in interdecadal TCGF changes, the 20-day low-passfiltered $850-\mathrm{hPa}$ relative vorticity was analyzed (Fig. 4). In JFM, when focusing on the interdecadal increases and decreases in large-scale relative vorticity along $10^{\circ} \mathrm{N}$, the increases span from $100^{\circ}$ to $150^{\circ} \mathrm{E}$ and the decreases span from $150^{\circ} \mathrm{E}$ to the date line (Fig. 4a). This dipole pattern is largely consistent with interdecadal changes in TCGF shown in Fig. 3a. Despite significant changes in the large-scale relative vorticity, TCGF in JFM remains unchanged, partly because the MDR in JFM is not fully dominated by changes in the vorticity fields. Besides, the TCGF is too low to produce statistically meaningful changes in this season. In AMJ, significant changes in the large-scale relative vorticity are found in the narrow region and scattered (Fig. 4b). A broad area of significant decrease in relative vorticity (an anomalous anticyclonic flow) occurs from the eastern Philippines Sea to the date line, but the location is irrelevant with MDR. In JAS, no significant changes in largescale relative vorticity are found in the central MDR (Fig. 4c). In the northwestern boundary of MDR from $20^{\circ}$ to $30^{\circ} \mathrm{N}$, 

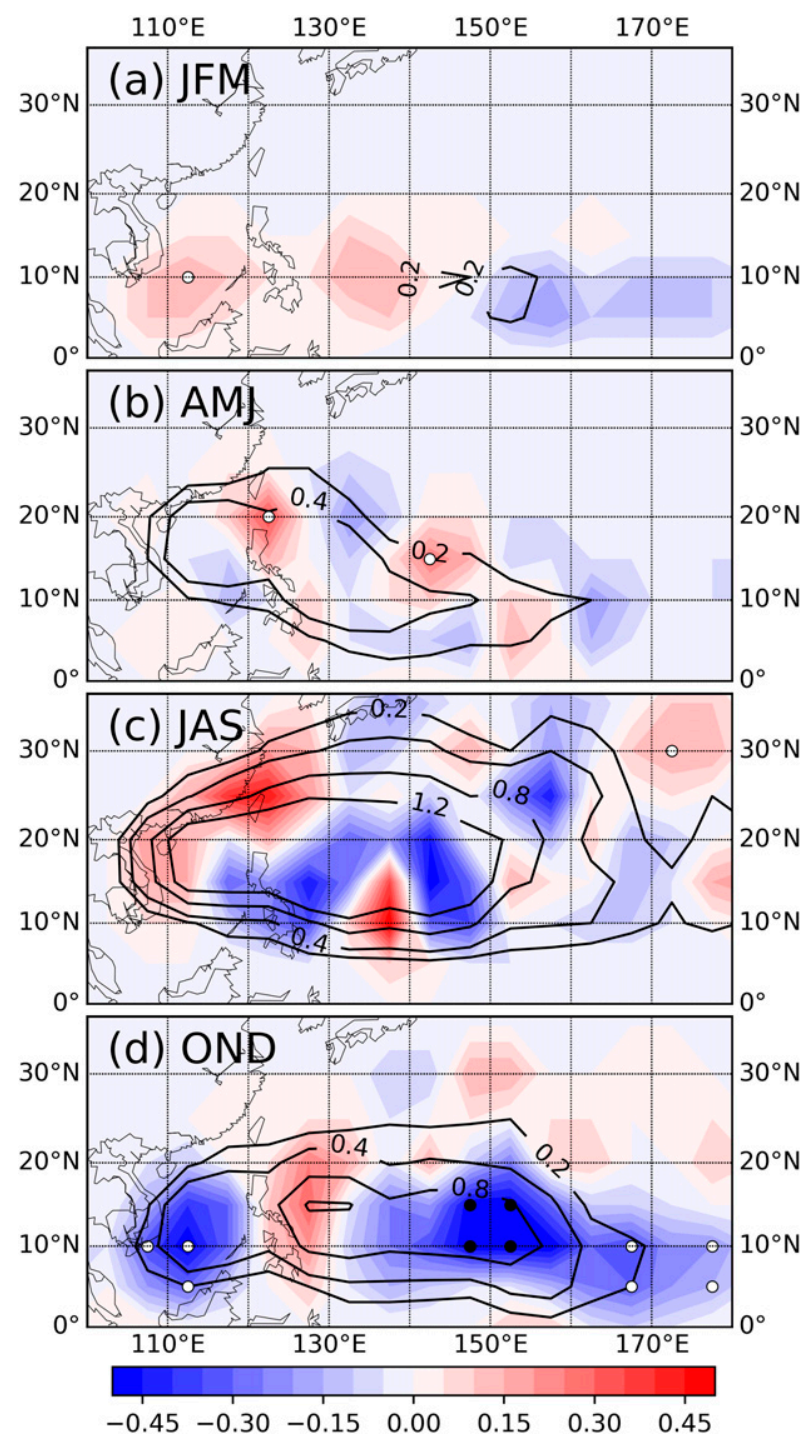

FIG. 3. TCGF climatology in 1979-2018 (contours) and difference between recent (1998-2018) and past (1979-97) periods (color shading) in (a) JFM, (b) AMJ, (c) JAS, and (d) OND. The white and black dots respectively represent significance at the $90 \%$ and $95 \%$ confidence levels between the two periods.

significant increases in relative vorticity are found, consistent with the slight TCGF increase shown in Fig. 3c. To the southeastern boundary of MDR (from the eastern Philippines Sea to the date line), a slight decrease in the large-scale relative vorticity is found with lack of significance. It can be said that the large-scale vorticity changes in interdecadal time scale do not significantly affect the total number of TCGF in JAS whereas smaller-spatial-scale or smaller-temporal-scale vorticity (i.e., interannual or intraseasonal) variations might influence TCGF changes in JAS. However, further analysis is necessary to be more confident. Last, in OND, the MDR is dominated by decrease in large-scale relative vorticity (a distinct anomalous anticyclone; Fig. 4d) including from the east and west northern Philippines to
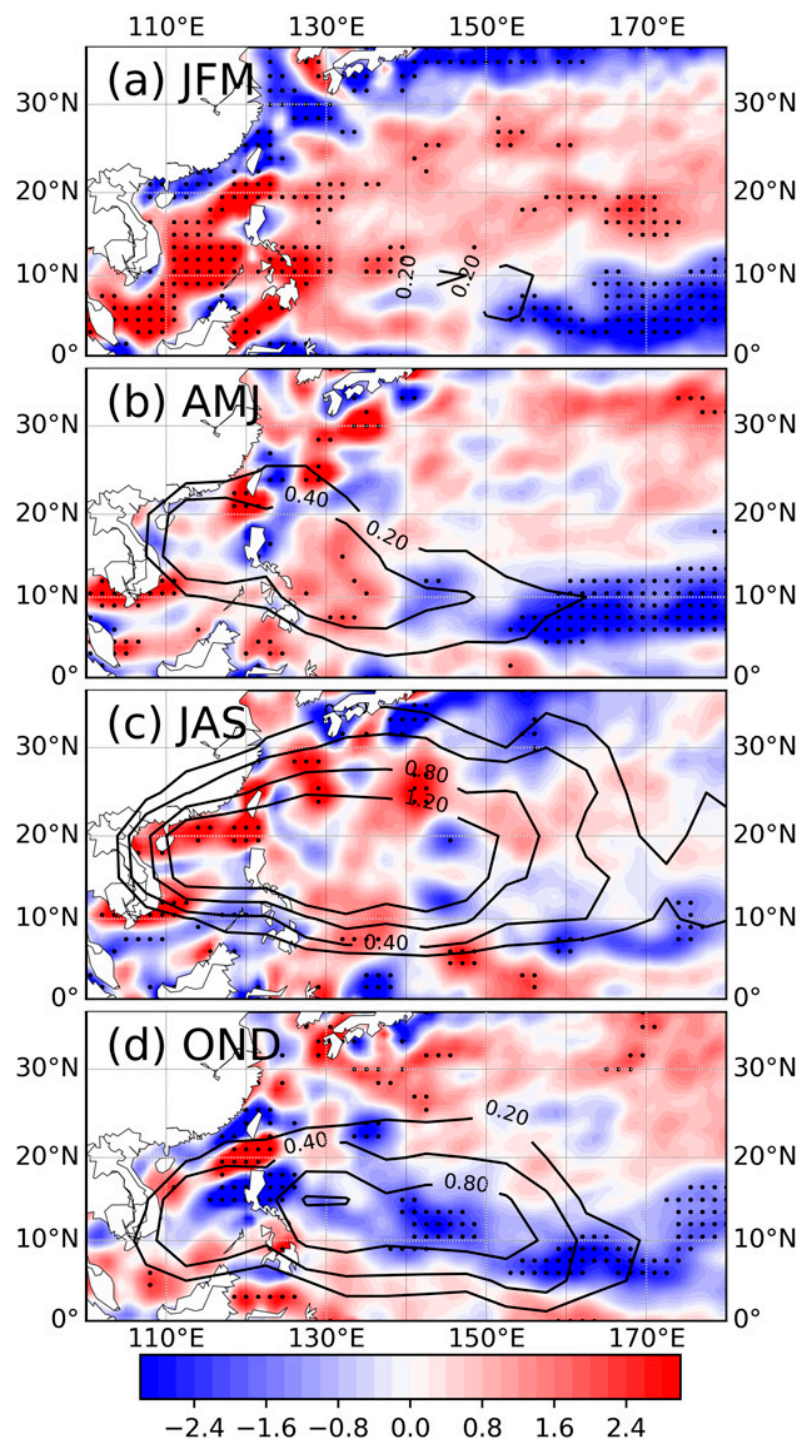

FIG. 4. The differences (1998-2018 minus 1979-97) of 20-day low-pass-filtered 850 -hPa relative vorticity (color shading; $10^{-6} \mathrm{~s}^{-1}$ ) for (a) JFM, (b) AMJ, (c) JAS, and (d) OND. The dots represent significance at the $95 \%$ confidence level between the two periods, and the contours are the seasonal TCGF climatology.

the date line. Contrary to the complex relative vorticity changes in JAS, the coherent changes over the entire MDR in OND can explain the recent reduction in TCGF during this season.

When focusing on the zonal extension of the anomalous anticyclone, the western boundary of anomalous anticyclone is located at approximately $140^{\circ}-150^{\circ} \mathrm{E}$ in $\mathrm{JFM}$, AMJ, and JAS, and at approximately $110^{\circ} \mathrm{E}$ in OND. To further compare the relevant environmental fields and to understand the key difference between OND and the other seasons, the seasons except for OND are combined for simplicity (i.e., January-September). Note that the overall conclusion is not significantly changed even if we compare with each season individually (see Fig. S1 in the online supplemental material). 

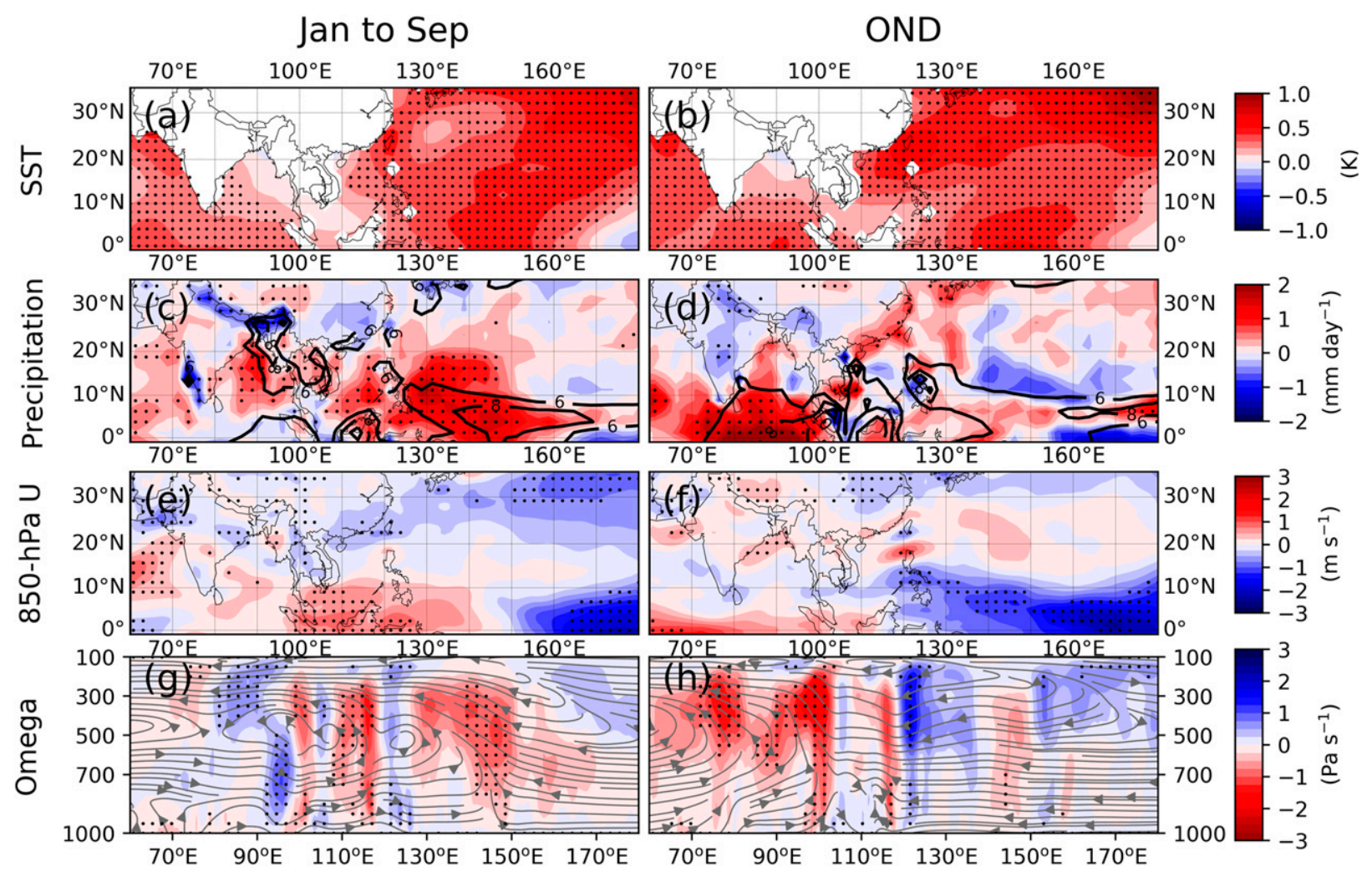

FIG. 5. The differences (1998-2018 minus 1979-97) in horizontal distributions in (left) January-September and (right) OND for (a),(b) SST (color shading; K); (c),(d) precipitation (color shading; $\mathrm{mm} \mathrm{day}^{-1}$ ); and (e),(f) 850-hPa zonal wind (color shading; $\mathrm{m} \mathrm{s}^{-1}$ ). The thick black

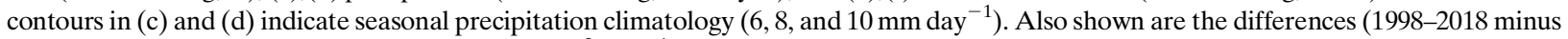
1979-97) in the vertical velocity (color shadings; $10^{-2} \mathrm{~Pa} \mathrm{~s}^{-1}$ ) and in the Walker circulation (meridional average from $0^{\circ}$ to $10^{\circ} \mathrm{N}$; streamlines) in (g) January-September and (h) OND. The dots represent significance at the $95 \%$ confidence level between the two periods.

Figures 5a and $5 \mathrm{~b}$ present the interdecadal changes in SST anomalies in January-September and OND. Both in JanuarySeptember and OND, significant SST warming is found over the tropical Indian Ocean and the tropical western Pacific. Relatively small SST changes are found near the date line in January-September and OND (referred to as La Niña-like warming). Quantitatively, the spatial correlation of SST anomalies in the tropics $\left(0^{\circ}-20^{\circ} \mathrm{N}, 60^{\circ} \mathrm{E}-180^{\circ}\right)$ between the two seasonal groups is 0.80 with $99 \%$ confidence level. This La Niña-like SST warming is also found in the composite of JFM, AMJ, and JAS (not shown). Whereas Hsu et al. (2014) suggested a possible relationship between the TCGF decrease in OND and the SST warming in the western Pacific, eastern North Pacific, and part of the Indian Ocean, the analysis in this study shows that the SST warming pattern is rather consistent between all seasons. Thus, the interdecadal changes in the tropical precipitation and associate equatorial easterly wind anomalies are further analyzed.

A similar situation-namely, different responses of largescale circulation to similar SST patterns between seasons-has been found and analyzed by Wu et al. (2017). They found that the location of the WNP anomalous anticyclone moves eastward from boreal summer to winter in developing El Niño years although the El Niño-related SST anomalies are almost identical between seasons. They explained this result on the basis of the climatological field of relative vorticity. The same approach was adopted in this study to investigate possible mechanisms. The spatial distribution of precipitation climatology (thick black contours) and its interdecadal changes (shadings) are shown in Figs. 5c and 5d. In January-September, the precipitation climatology is concentrated in the tropical western Pacific and the Indochinese Peninsula. In terms of interdecadal change, precipitation increase is significant over the tropical western Pacific (at approximately $0^{\circ}-10^{\circ} \mathrm{N}, 130^{\circ}-$ $160^{\circ} \mathrm{E}$ ) and around the Indochinese Peninsula (shadings in Fig. 5c). In OND, the seasonal mean precipitation (thick black contours in Fig. 5d) is concentrated along the tropics. When we compare that in the tropical western Pacific and the tropical Indian Ocean, relatively heavier precipitation occurs over the tropical Indian Ocean (at approximately $0^{\circ}-10^{\circ} \mathrm{N}, 70^{\circ}-100^{\circ} \mathrm{E}$ ) in climatology. Interdecadal increase in precipitation is also the highest and significant in the tropical Indian Ocean. In fact, spatial correlations between seasonal means and interdecadal changes of precipitation are 0.39 and 0.21 for January-September and OND over the tropical band $\left(0^{\circ}-10^{\circ} \mathrm{N}, 60^{\circ} \mathrm{E}-180^{\circ}\right)$, respectively, all of which are statistically significant at $99 \%$ confidence levels. Note that the spatial correlations are also statistically significant for the individual seasons (i.e., JFM, AMJ, and JAS), which range from 0.22 to 0.29 . 
The different changes between OND and January-September are likely associated with the rich-get-richer mechanism, which was suggested by Chou and Neelin (2004). According to them, under global warming, precipitation tends to noticeably increase in climatological convergence regions and to decrease in subsidence ones. Global warming may moisten the atmospheric boundary layer (ABL), which decreases the gross moist static stability. Consequently, convection is more enhanced over stronger convective regions. The direct moisture effect can be another mechanism although it is a secondary effect. Moisture enhancement in the troposphere may directly increase precipitation in climatological convective areas. Similarly, in our result, the extensive SST warming over the WNP may supply more moisture to the ABL, so that convection can be enhanced over convergence zones with climatologically large precipitation. Actually, for all seasons, the low-level moisture significantly increases over the tropical band where SST rise is notable (not shown).

In accordance with the precipitation changes in different ocean basins between January-September and OND, associated $850-\mathrm{hPa}$ easterly wind anomalies are shown in Figs. 5e and 5f. where positive and negative values indicate an increase in anomalous westerly and easterly winds, respectively. In January-September, anomalous westerly and easterly winds are clearly shown in the tropics, converging at $\sim 140^{\circ}-150^{\circ} \mathrm{E}$ (Fig. 5e). The region where anomalous tropical wind converges is consistent with the region with enhanced precipitation region (Fig. $5 \mathrm{c}$ ). The anomalous easterlies from $140^{\circ}$ to the date line along the tropics would induce anomalous horizontal wind shear over the subtropics, which eventually leads to the anomalous anticyclone in the WNP (Figs. 4a-c). In OND, the anomalous easterly dominates the entire tropical western Pacific from $120^{\circ} \mathrm{E}$ to the date line (Fig. 5f). The anomalous westerly is confined in the tropical Indian Ocean close to the equator. These tropical wind anomalies converge at approximately $110^{\circ}-120^{\circ} \mathrm{E}$. In this season, the precipitation enhancement locates westward to the tropical wind convergence region (Fig. 5d). The large-scale increase in the anomalous easterly wind traveling the entire tropical western Pacific would induce anomalous horizontal wind shear over the entire subtropical WNP as well as the attendant anomalous anticyclone in the WNP (Fig. 4d).

In Figs. $5 \mathrm{~g}$ and $5 \mathrm{~h}$, the interdecadal changes in vertical velocity are shown (shadings) with associated changes in the Walker circulation (calculated within $0^{\circ}-10^{\circ} \mathrm{N}$ ). In terms of the Walker circulation, the focus is on the interdecadal changes in ascending branches of the circulation. In January-September, the ascending anomalies (red shadings in Fig. $5 \mathrm{~g}$ ) display two peaks, at approximately $110^{\circ} \mathrm{E}$ and at $140^{\circ}-150^{\circ} \mathrm{E}$. The ascending branch at approximately $140^{\circ}-150^{\circ} \mathrm{E}$ is consistent with lower tropospheric wind convergence (streamlines in Figs. $5 \mathrm{~g}, \mathrm{e}$ ). These locations are also consistent with the positive precipitation anomalies shown in Fig. 5c. In OND, the anomalous ascending motion is located over $70^{\circ}-100^{\circ} \mathrm{E}$ (i.e., the tropical Indian Ocean). This location of ascending anomaly is consistent with lower tropospheric wind convergence (streamlines in Figs. 5h,f) as well as precipitation enhancement (Fig. 5d). Thus, the analysis of interdecadal changes in the Walker circulation is consistent with previous investigation on the changes in precipitation and 850-hPa easterly wind.
On the other hand, many previous studies suggested that the stronger vertical wind shear associated with the enhanced Walker circulation is the most important factor to reduce TCGF in the eastern part of WNP in a recent decade (Liu and Chan 2013; Choi et al. 2015; Zhang et al. 2018; Liu et al. 2019). However, in this study, a lack of significant changes over MDR is found in vertical wind shear to explain the reduction in TCGF (not shown). As a thermodynamics factor, the low-level relative humidity was also analyzed. However, the change of relative humidity is favorable for TC genesis, and hence it cannot explain the recent TCGF decrease (not shown). This is consistent with previous studies (Chan 2009; Park et al. 2013; Hsu et al. 2014), which highlighted that dynamic factors are more dominant than thermodynamic factors in TC genesis over the WNP.

\section{Summary and conclusions}

In this study, the seasonal inhomogeneity of interdecadal changes in TCGF was investigated and a possible mechanism for such changes was proposed in a large-scale perspective. The results clearly exhibited the total TCGF reduction over the last two decades compared to the previous two were concentrated in the late season (OND). Spatially, the interdecadal changes of TCGF in OND were significant over a wide region of MDR, whereas the changes in the other seasons (January-September) are likely to occur locally with lack of significance.

Examination of recent changes in large-scale relative vorticity revealed anticyclone anomalies over the tropical Pacific in all seasons, but their zonal extent and significance differed by season. In JFM and AMJ, significant anticyclone anomalies were observed over the eastern tropical western Pacific. However, the anticyclone anomalies appeared in the eastern boundary of MDR, not directly influencing TCGF in these seasons. In JAS, the anticyclone anomaly location was analogous to that in JFM and AMJ, but the anomaly was insignificant. However, in OND, significant anticyclone anomalies occurred over almost the entire WNP, and particularly residing within the MDR. Thus, such existence of large-scale anomalous anticyclones would disturb TC formation in OND and eventually cause an overall reduction in TCGF.

These systematic changes in large-scale relative vorticity corresponded to different changes in the ascending and lower branches of the Walker circulation in each season in the warming climate. Although the SST warming pattern in the tropics was consistent across the four seasons (La Niña-like SST warming), the precipitation enhancement occurred in different regions between OND and January-September. Tropical precipitation was enhanced over the tropical Indian Ocean in OND and over the tropical western Pacific in the other seasons. In contrast with the other seasons, the enhanced precipitation in the tropical Indian Ocean in OND produced the most extensive anomalous easterly wind along the tropical Pacific. The extensive anomalous easterly wind produced a meridional wind gradient in the subtropical WNP, which resulted in the wide-ranging anticyclone anomaly in OND. Our findings imply that considering the influence of seasonal mean tropical convection is important for understanding large-scale circulation response to future SST warming in the WNP. 
Meanwhile, frequency changes of intraseasonal oscillation (ISO) can be another potential factor to explain the recent TCGF reduction (Hsu et al. 2017; Huangfu et al. 2017, 2018; Zhao and Wang 2019). Particularly, for JAS, we have calculated the environmental field changes for shorter time scales (i.e., 12 years before/after 1997), in which total TCGF has significantly decreased as mentioned. The broad SST warming is found for the period despite the cold anomaly around the Philippines. Similarly, we found that tropical precipitation increased where the climatological values are high (i.e., at approximately $130^{\circ}-145^{\circ} \mathrm{E}$ ). Consistent with the tropical precipitation anomaly, the easterly wind anomalies were limited from $145^{\circ} \mathrm{E}$ to the date line. Thus, the TCGF reduction in the southeastern quadrant of WNP accounts for only $49 \%$ of entire TCGF decreases in JAS for the period. The other $50 \%$ of TCGF decreases was explained by the southwestern and northeastern quadrants of WNP, possibly associated with other factors on smaller scales. It would be meaningful to investigate the contribution of the ISO. This remains for our further study.

Acknowledgments. This work was funded by the National Research Foundation of Korea (Grants 2019R1I1A3A01058100 and 2020R1A4A3079510), the Korea Environment Industry and Technology Institute (KEITI) through the Climate Change Correspondence Program by the Korea Ministry of Environment (MOE) (2018001310004), and the Korea Meteorological Administration Research and Development Program under Grant KMI2020-00610.

\section{REFERENCES}

Adler, R. F., and Coauthors, 2003: The version-2 Global Precipitation Climatology Project (GPCP) monthly precipitation analysis (1979present). J. Hydrometeor., 4, 1147-1167, https://doi.org/10.1175/ 1525-7541(2003)004<1147:TVGPCP > 2.0.CO;2.

Chan, J. C. L., 2009: Thermodynamic control on the climate of intense tropical cyclones. Proc. Roy. Soc. London, A465, 3011-3021, https://doi.org/10.1098/rspa.2009.0114.

Choi, Y., K.-J. Ha, C.-H. Ho, and C. E. Chung, 2015: Interdecadal change in typhoon genesis condition over the western North Pacific. Climate Dyn., 45, 3243-3255, https://doi.org/10.1007/ s00382-015-2536-y.

Chou, C., and J. D. Neelin, 2004: Mechanisms of global warming impacts on regional tropical precipitation. J. Climate, 17, 2688-2701, https://doi.org/10.1175/1520-0442(2004)017<2688: MOGWIO $>2.0 . \mathrm{CO} ; 2$.

Chu, P.-S., 2002: Large-scale circulation features associated with decadal variations of tropical cyclone activity over the central North Pacific. J. Climate, 15, 2678-2689, https:// doi.org/10.1175/1520-0442(2002)015<2678:LSCFAW>2.0. $\mathrm{CO} ; 2$.

Dee, D. P., and Coauthors, 2011: The ERA-Interim reanalysis: Configuration and performance of the data assimilation system. Quart. J. Roy. Meteor. Soc., 137, 553-597, https://doi.org/ 10.1002/qj.828.

Fan, T., S. Xu, F. Huang, and J. Zhao, 2019: The phase differences of the interdecadal variabilities of tropical cyclone activity in the peak and late seasons over the western North Pacific. Theor. Appl. Climatol., 136, 77-83, https://doi.org/10.1007/ s00704-018-2465-x.
Fu, B., M. S. Peng, T. Li, and D. E. Stevens, 2012: Developing versus nondeveloping disturbances for tropical cyclone formation. Part II: Western North Pacific. Mon. Wea. Rev., 140, 1067-1080, https://doi.org/10.1175/2011MWR3618.1.

He, H., J. Yang, D. Gong, R. Mao, Y. Wang, and M. Gao, 2015: Decadal changes in tropical cyclone activity over the western North Pacific in the late 1990s. Climate Dyn., 45, 3317-3329, https://doi.org/10.1007/s00382-015-2541-1.

Hong, C.-C., Y.-K. Wu, and T. Li, 2016: Influence of climate regime shift on the interdecadal change in tropical cyclone activity over the Pacific Basin during the middle to late 1990s. Climate Dyn., 47, 2587-2600, https://doi.org/10.1007/s00382-0162986-x.

Hsu, P.-C., P.-S. Chu, H. Murakami, and X. Zhao, 2014: An abrupt decrease in the late-season typhoon activity over the western North Pacific. J. Climate, 27, 4296-4312, https://doi.org/10.1175/ JCLI-D-13-00417.1.

—_, T.-H. Lee, C.-H. Tsou, P.-S. Chu, Y. Qian, and M. Bi, 2017: Role of scale interactions in the abrupt change of tropical cyclone in autumn over the western North Pacific. Climate Dyn., 49, 3175-3192, https://doi.org/10.1007/s00382016-3504-x.

Huang, B., and Coauthors, 2017: NOAA Extended Reconstructed Sea Surface Temperature (ERSST), version 5. NOAA National Centers for Environmental Information, accessed 31 January 2019, https://doi.org/10.7289/V5T72FNM.

Huangfu, J., R. Huang, W. Chen, T. Feng, and L. Wu, 2017: Interdecadal variation of tropical cyclone genesis and its relationship to the monsoon trough over the western North Pacific. Int. J. Climatol., 37, 3587-3596, https://doi.org/10.1002/ joc. 4939 .

,-- , and -2018 : Interdecadal variation of tropical cyclone genesis and its relationship to the convective activities over the central Pacific. Climate Dyn., 50, 1439-1450, https:// doi.org/10.1007/s00382-017-3697-7.

Kim, J.-H., C.-H. Ho, and P.-S. Chu, 2010: Dipolar redistribution of summertime tropical cyclone genesis between the Philippine Sea and the northern South China Sea and its possible mechanisms. J. Geophys. Res. Atmos., 115, D06104, https:// doi.org/10.1029/2009JD012196.

Kohyama, T., D. L. Hartmann, and D. S. Battisti, 2017: La Niñalike mean-state response to global warming and potential oceanic roles. J. Climate, 30, 4207-4225, https://doi.org/10.1175/ JCLI-D-16-0441.1.

Kosaka, Y., and S.-P. Xie, 2013: Recent global-warming hiatus tied to equatorial Pacific surface cooling. Nature, 501, 403-407, https://doi.org/10.1038/nature12534.

Liu, C., W. Zhang, X. Geng, M. F. Stuecker, and F.-F. Jin, 2019: Modulation of tropical cyclones in the southeastern part of western North Pacific by tropical Pacific decadal variability. Climate Dyn., 53, 4475-4488, https://doi.org/10.1007/s00382019-04799-w.

Liu, K. S., and J. C. L. Chan, 2013: Inactive period of western North Pacific tropical cyclone activity in 1998-2011. J. Climate, 26, 2614-2630, https://doi.org/10.1175/JCLI-D-12-00053.1.

Park, D.-S. R., C.-H. Ho, J.-H. Kim, and H.-S. Kim, 2011: Strong landfall typhoons in Korea and Japan in a recent decade. J. Geophys. Res., 116, D07105, https://doi.org/10.1029/ 2010JD014801.

$[,-, \ldots$, and — 2013: Spatially inhomogeneous trends of tropical cyclone intensity over the western North Pacific for 1977-2010. J. Climate, 26, 5088-5101, https://doi.org/10.1175/ JCLI-D-12-00386.1. 
Vecchi, G. A., and B. J. Soden, 2007: Effect of remote sea surface temperature change on tropical cyclone potential intensity. Nature, 450, 1066-1070, https://doi.org/10.1038/nature06423.

Wu, B., T. Zhou, and T. Li, 2017: Atmospheric dynamic and thermodynamic processes driving the western North Pacific anomalous anticyclone during El Niño. Part II: Formation processes. J. Climate, 30, 9637-9650, https://doi.org/10.1175/ JCLI-D-16-0495.1.

Zhang, L., L. Wu, and L. Yu, 2011: Oceanic origin of a recent La Niña-like trend in the tropical Pacific. Adv. Atmos. Sci., 28, 1109-1117, https://doi.org/10.1007/s00376-010-0129-6.

Zhang, W., G. A. Vecchi, H. Murakami, G. Villarini, T. L. Delworth, X. Yang, and L. Jia, 2018: Dominant role of
Atlantic multidecadal oscillation in the recent decadal changes in western North Pacific tropical cyclone activity. Geophys. Res. Lett., 45, 354-362, https://doi.org/10.1002/ 2017GL076397.

Zhao, H., and C. Wang, 2019: On the relationship between ENSO and tropical cyclones in the western North Pacific during the boreal summer. Climate Dyn., 52, 275-288, https://doi.org/ 10.1007/s00382-018-4136-0.

Zhao, J., R. Zhan, Y. Wang, and H. Xu, 2018: Contribution of the interdecadal Pacific Oscillation to the recent abrupt decrease in tropical cyclone genesis frequency over the western North Pacific since 1998. J. Climate, 31, 8211-8224, https://doi.org/ 10.1175/JCLI-D-18-0202.1. 